\title{
Down-regulation of AMPD3 Is Associated With Poor Survival in Head and Neck Squamous Cell Carcinoma
}

\author{
CHENG-MING HSU ${ }^{1,2}$, SHUN-FU CHANG ${ }^{3}$, YAO-TE TSAI ${ }^{1}$, MING-SHAO TSAI ${ }^{1}$, \\ GENG-HE CHANG ${ }^{1}$, HUNG-CHIN CHEN ${ }^{1}$, PING-CHUNG HUANG ${ }^{1}$, CHIEN-AN KO ${ }^{1}$, \\ CHIN-YUAN WU ${ }^{4}$, SHENG-FUNG LIN ${ }^{5}$ and MING-YU YANG ${ }^{6,7}$ \\ ${ }^{1}$ Department of Otolaryngology-Head and Neck Surgery, Chang Gung Memorial Hospital, Chiayi, Taiwan, R.O.C.; \\ ${ }^{2}$ Department of Medicine, College of Medicine, Chang Gung University, Tao-Yuan, Taiwan, R.O.C.; \\ ${ }^{3}$ Department of Medical Research and Development, \\ Chiayi Chang Gung Memorial Hospital, Chiayi, Taiwan, R.O.C.; \\ ${ }^{4}$ Department of Traditional Chinese Medicine, Chang Gung Memorial Hospital, Chiayi, Taiwan, R.O.C.; \\ ${ }^{5}$ Division of Hematology and Oncology, Department of Internal Medicine, \\ E-Da Hospital, Kaohsiung, Taiwan, R.O.C.; \\ ${ }^{6}$ Graduate Institute of Clinical Medical Sciences, College of Medicine, \\ Chang Gung University, Tao-Yuan, Taiwan, R.O.C.; \\ ${ }^{7}$ Department of Otolaryngology, Kaohsiung Chang Gung Memorial Hospital, Kaohsiung, Taiwan, R.O.C.
}

\begin{abstract}
Background: Adenosine monophosphate deaminase 3 (AMPD3) is an isoenzyme involved in the regulation of the energetic metabolism of mammalian cells. Cancer cells have a high demand for their energy supply. This experimental study aimed to illustrate the role of AMPD3 in human head and neck squamous cell carcinoma (HNSCC). Materials and Methods: Real-time quantitative reverse transcription-polymerase chain reaction was used to investigate the expression of the AMPD3 gene in human HNSCC tissues to assess the changes in cancerous and noncancerous parts and the correlation with different tumor behavior. The functions of AMPD3 were investigated using wound-healing and migration assays. Results: AMPD3 was significantly down-regulated in cancerous tissues of HNSCC $(p=0.001)$ and this was correlated with more advanced tumor and clinical stages. Patients with high expression had
\end{abstract}

This article is freely accessible online.

Correspondence to: Ming-Yu Yang, Graduate Institute of Clinical Medical Sciences, College of Medicine, Chang Gung University, 259 Wen-Hwa $1^{\text {st }}$ Road, Kwei-Shan 333 Tao-Yuan, Taiwan, R.O.C. Tel: +886 77317123 ext. 8865, e-mail: yangmy@mail.cgu.edu and Sheng-Fung Lin, Division of Hematology and Oncology, Department of Internal Medicine, E-Da Hospital, Kaohsiung 82445, Taiwan, R.O.C. E-mail: shlin@kmu.edu.tw

Key Words: AMP-deaminase 3, head and neck squamous cell carcinoma, real-time quantitative RT-PCR, transwell assay, migration assay, patient survival. better 5-year survival. AMPD3 knock-down in SCC-4 and SCC-25 cells demonstrated reduction of proliferation but increased migration and invasion. Conclusion: To our knowledge, this is the first report evidencing the expression pattern of AMPD3 in HNSCC and demonstrated that high AMPD3 expression might represent a good prognostic biomarker. AMPD3 may have an antiproliferative potential but its down-regulation may not contribute to reducing the migration and invasion of HNSCC cells.

Head and neck cancer is increasing in incidence in developing countries due to a changing lifestyle (1). Head and neck squamous cell carcinoma (HNSCC) is the is among the top ten causes of cancer-related death $(2,3)$. In Taiwan, the prevalence of HNSCC is growing rapidly and it represents the fifth leading cause of cancer death, with 3,000 deaths every year (4). In 2016, oral, oropharyngeal, and hypopharyngeal cancers together ranked as the sixth most common cancer in Taiwan, being even more common among Taiwanese men (4). The most important risk factors for development of HNSCC, recognized through epidemiological studies, include alcohol and tobacco use, betel quid chewing, viral infection (human papillomavirus and Epstein-Barr virus), and genetic polymorphism or damage $(5,6)$.

HNSCC may be curable with surgery, radiation and chemotherapy in its early stages. Both surgery and concurrent chemoradiotherapy play an important role in standard treatment. However, despite aggressive treatments with combinations of surgery, radiation and chemotherapy, little progress has been made towards better outcomes (7). 
Recurrence and metastasis occur after primary treatment in advanced stage cases and are associated with significant morbidity and mortality. Therefore, biomarkers for early diagnosis or prognosis HNSCC remain a focus of research for this disease.

Adenosine monophosphate deaminase 3 (AMPD3; EC 3.5.4.6), is a highly regulated oligomeric enzyme, catalyzing the irreversible deamination of adenylic acids (8-10). There are three members of the AMPD family: AMPD1, AMPD2 and AMPD3 (11). AMPDs play important role in stabilization of adenylate energy charge and regulation of the size of purine nucleotides pool in several types of animal tissues. The hydrolytic deamination of AMP to inosine monophosphate is catalyzed by AMPDs, AMPDs are involved in the purine nucleotide cycle and carbohydrate metabolism (12). Mutations in the AMPD3 gene can lead to clinically asymptomatic disease, for example: erythrocyte AMPD deficiency (10). A recent report suggested that AMPD2 and AMPD3 may be potential targets for cancer treatment (13). Further study is needed to determine the significance of altered $A M P D$ genes in cancer.

As far as we are aware, there is no study about the expression of AMPD3 gene in human HNSCC. Therefore, in this study we investigated the expression of the AMPD3 gene in human HNSCC tissues to determine if there was any correlation with malignancy and disease stages. The experimental studies presented here illustrate the role of AMPD3 in HNSCC.

\section{Materials and Methods}

Patients and samples. This study enrolled 57 patients (55 men and two women, aged 34-82 years), diagnosed with HNSCC and undergoing surgery at the Department of Otolaryngology, Kaohsiung Chang Gung Memorial Hospital, Kaohsiung City, Taiwan. The TNM tumor staging system of as defined by the American Joint Committee on Cancer (14) was used. Patients' clinical and pathological characteristics, including gender, age, tumor staging, nodal staging, clinical staging, tumor site, tumor size and survival are shown in Table I. For the correlation analysis of AMPD3 expression, we divided the enrolled patients into disease-severity groups based on: (i) Early clinical stage (stages I and II) and advanced stage (stages III and IV); and (ii) tumor stage (T1/T2, and T3/T4); and (iii) tumor size ( $\geq 3$ and $<3 \mathrm{~cm}$ ); and (iv) survival (Table II).

Samples of tumor and the adjacent noncancerous tissues were snap-frozen in liquid nitrogen immediately after resection and stored until use.

This study was approved by the Institutional Review Board of the Kaohsiung Chang Gung Memorial Hospital (no. 100-4455A3) and written informed consent was obtained from all patients prior to tissue acquisition. This study was conducted in full accordance with the guidelines stated by the Declaration of Helsinki.

Expression of AMPD3 gene analyzed by real-time quantitative reverse transcriptase-polymerase chain reaction ( $q R T-P C R)$. Total RNA was extracted from cancerous and noncancerous tissues of patients with
Table I. Characteristics of patients with head and neck squamous cell carcinoma.

\begin{tabular}{|c|c|c|}
\hline Characteristic & Subgroup & Value \\
\hline \multirow[t]{2}{*}{ Gender, n (\%) } & Male & $55(96.4 \%)$ \\
\hline & Female & $2(3.8 \%)$ \\
\hline Age, years & Median (range) & $54(34-82)$ \\
\hline \multirow[t]{4}{*}{ T-Stage, n (\%) } & 1 & $7(12.2 \%)$ \\
\hline & 2 & $20(35.1 \%)$ \\
\hline & 3 & $15(26.3 \%)$ \\
\hline & 4 & $15(26.3 \%)$ \\
\hline \multirow[t]{6}{*}{ N-Stage, n (\%) } & 0 & $28(49.1 \%)$ \\
\hline & 1 & $7(12.2 \%)$ \\
\hline & $2 \mathrm{a}$ & $2(3.5 \%)$ \\
\hline & $2 b$ & $13(22.8 \%)$ \\
\hline & $2 \mathrm{c}$ & $4(7.0 \%)$ \\
\hline & 3 & $0(0 \%)$ \\
\hline \multirow[t]{6}{*}{ Site, n (\%) } & Oral cavity & $27(47.3 \%)$ \\
\hline & Oropharynx & $9(15.8 \%)$ \\
\hline & Supraglottic & $2(3.5 \%)$ \\
\hline & Larynx & $5(8.7 \%)$ \\
\hline & Hypopharynx & $12(21.1 \%)$ \\
\hline & Parotid & $2(3.5 \%)$ \\
\hline \multirow[t]{4}{*}{ Clinical stage, n (\%) } & I & $5(8.7 \%)$ \\
\hline & II & $12(21.1 \%)$ \\
\hline & III & $10(17.5 \%)$ \\
\hline & IV & $30(52.6 \%)$ \\
\hline \multirow[t]{2}{*}{ Tumor size, n (\%) } & $<3 \mathrm{~cm}$ & $23(40.3 \%)$ \\
\hline & $\geq 3 \mathrm{~cm}$ & $34(59.6 \%)$ \\
\hline \multirow[t]{2}{*}{ Status at 5 years, $\mathrm{n}(\%)$} & Died & $32(56.1 \%)$ \\
\hline & Survived & $25(43.9 \%)$ \\
\hline
\end{tabular}

HNSCC using TRIzol reagent (Invitrogen, Carlsbad, CA, USA). Spectrophotometric $\mathrm{OD}_{260} / \mathrm{OD}_{280}$ measurement was used to determine the amount of RNA and High Capacity cDNA Reverse Transcription Kit (Applied Biosystems, Foster City, CA, USA) was used to generate cDNA from $2 \mathrm{mg}$ RNA according to the manufacturer's protocols. The expression of AMPD3 gene was analyzed using AMPD3 TaqManâ Gene Expression Assays (Hs00983726_m1) purchased from Applied Biosystems and the expression of b-actin $(A C T B)$ gene was also analyzed for normalizing the expression of AMPD3. All reactions were carried out in a $10-\mu \mathrm{l}$ final volume containing $25 \mathrm{ng}$ cDNA (as total input RNA), $0.5 \mu \mathrm{l} 20 \times$ TaqManâ Gene Expression Assay, and $5 \mu \mathrm{l} 2 \times$ TaqManâ Universal PCR Master Mix (Applied Biosystems). The PCR cycling parameters $\left(95^{\circ} \mathrm{C}\right.$ for $10 \mathrm{~min}$ followed by 40 cycles of $95^{\circ} \mathrm{C}$ for $20 \mathrm{~s}$ and $60^{\circ} \mathrm{C}$ for $1 \mathrm{~min}$ ) were set and run in an ABI 7500 Fast Real-Time System (Applied Biosystems). The relative threshold cycle $(\triangle \mathrm{C} t)$ of AMPD3 gene was obtained by normalizing the threshold cycles for AMPD3 gene to those for $A C T B$ gene of the same sample, i.e., $-\Delta \mathrm{C} t[-(\mathrm{C} t$ of $A M P D 3-\mathrm{C} t$ of $A C T B)]$. Thus, a higher $-\Delta \mathrm{C} t$ value represents lower expression of $A M P D 3$ and vice versa.

Immunohistochemical staining of AMPD3 proteins. Immunohistochemical staining was performed on cancerous tissues and the adjacent noncancerous tissues of patients with HNSCC. Tissue sections were incubated with monoclonal antibody against human AMPD3 proteins (1:200 dilution; Abcam Inc., Boston, MA, USA) 
Table II. Characteristics of patients according to expression of adenosine monophosphate deaminase 3 (AMPD3).

\begin{tabular}{llcc}
\hline & & \multicolumn{2}{c}{ AMPD3 expression } \\
\cline { 3 - 4 } Characteristic & & Low $(\mathrm{n}=30)$ & High $(\mathrm{n}=27)$ \\
\hline Gender, n (\%) & Male & $28(93.3 \%)$ & $27(100 \%)$ \\
& Female & $2(6.7 \%)$ & $0(\%)$ \\
Age, years & Median (range) & $57.6(36-82)$ & $53.2(34-78)$ \\
Follow-up, days & Mean \pm SD & $2,023.53 \pm 1,654.66$ & $2,547.85 \pm 1,203.43$ \\
Expression, mean \pm SEM* & $1+2$ & & $-1.55 \pm 1.82(\mathrm{n}=12)$ \\
Clinical stage & $3+4$ & $-2.96 \pm 1.85(\mathrm{n}=5)$ & $-1.29 \pm 2.20(\mathrm{n}=15)$ \\
& $1+2$ & $-3.99 \pm 2.45(\mathrm{n}=25)$ & $-1.27 \pm 1.75(\mathrm{n}=17)$ \\
T-Stage & $3+4$ & $-3.49 \pm 2.16(\mathrm{n}=10)$ & $-1.63 \pm 2.48(\mathrm{n}=10)$ \\
& $\geq 3 \mathrm{~cm}$ & $-3.99 \pm 2.50(\mathrm{n}=20)$ & $-1.63 \pm 2.29(\mathrm{n}=16)$ \\
Tumor size & $<3 \mathrm{~cm}$ & $-4.50 \pm 2.66(\mathrm{n}=19)$ & $-1.08 \pm 1.55(\mathrm{n}=11)$ \\
Status at 5 years & Died & $-2.74 \pm 1.43(\mathrm{n}=11)$ & $11(40.7 \%)$ \\
& Survived & $21(70.0 \%)$ & $16(59.3 \%)$
\end{tabular}

*Determined as $-\Delta \Delta \mathrm{Ct}[(-\Delta \mathrm{Ct}$ of tumor $)-(-\Delta \mathrm{Ct}$ of normal tissue $)]$. Higher $-\Delta \Delta \mathrm{Ct}$ values represent higher expression of AMPD3 gene and vice versa. $p$-Values were derived from Student's $t$-test, except for sex and survival, which used chi-square test. The cut-off value of $-\Delta \Delta \mathrm{Ct}$ for dividing groups by AMPD3 expression was 0.9 .

for $1 \mathrm{~h}$ then incubated with biotinylated goat anti-mouse antibody for $30 \mathrm{~min}$. The spcific binding of the secondary antibody to the primary antibody was visualized using a horseradish peroxidasediaminobenzidine staining kit (Sigma-Aldrich, St Louis, MO, USA) and qualitatively examined using a Zeiss microscope (Zeiss, Gottingen, Germany).

Cell cultures and transfection. The four HNSCC cell lines used in this study, SCC-4, SCC-25, FaDu and Detroit 562, were purchased from the Food Industry Research and Development Institute, Taiwan. These cells were maintained at $37^{\circ} \mathrm{C}$ with $5 \% \mathrm{CO}_{2}$ in Minimum Essential Medium Eagle-F12 medium (Invitrogen) containing 10\% fetal bovine serum and $0.4 \mu \mathrm{g} / \mathrm{ml}$ hydrocortisone (Sigma-Aldrich). SCC-4 and SCC-25 were used for the transient knockdown of $A M P D 3$. Briefly, cells $(4,000$ cells/well) were transfected with AMPD3 Stealth siRNA (ThermoFisher Scientific, Watham, MA, USA) or control siRNA (ThermoFisher) per well by using $1 \mu \mathrm{l}$ of Lipofectamine 2000 (Invitrogen) according to the manufacturer's instructions and cells were harvested after transfection.

Western blotting. For western blotting, $10 \mu \mathrm{g}$ of the total lysates of SCC4, SCC-25, FaDu and Detroit 562 cells were separated using $6 \%$ to $15 \%$ sodium dodecyl sulfate-polyacrylamide gel electrophoresis and transferred to a polyvinylidene fluoride membrane (Millipore, Darmstadt, Germany). To detect the protein level of AMPD3, the membrane was incubated with AMPD3 antibody (ab194361, 1:1,000 dilution; Abcam) and internal control $\beta$-actin antibody (1:5,000 dilution; Abcam). Horseradish peroxidaseconjugated goat anti-rabbit Immunoglobulin G (IgG) $(1: 1,000$ dilution; Cell Signaling Technologies, Danvers, MA, USA) was used as secondary antibody for qualitative analysis.

Cell-cycle analysis. Non-transfected cells $\left(5 \times 10^{5}\right)$ were washed in phosphate-buffered saline, fixed with cold $70 \%$ ethanol, and incubated with $25 \mu \mathrm{g}$ RNAse A (Sigma-Aldrich) for $1 \mathrm{~h}$ at $37^{\circ} \mathrm{C}$. Prior to analysis, $25 \mu \mathrm{l}(5 \mathrm{mg} / \mathrm{ml})$ of propidium iodide (Sigma-
Aldrich) was added and stained cells was analyzed on a FACSCalibur flow cytometer (Becton-Dickinson, San Jose, CA, USA). The distribution of the cell population in sub- $G_{1}, G_{0} / G_{1}, S$, or $\mathrm{G}_{2} / \mathrm{M}$ phases were calculated from histograms.

3-(4,5-Dimethylthiazol-2-yl)-2,5-diphenyltetrazolium bromide (MTT) assay. The percentages of metabolically active SCC-4 and SCC-25 cells were determined on the basis of the mitochondrial conversion of MTT into formazine. In brief, cells transfected with $A M P D 3$ siRNA or control siRNA were incubated for different periods of time then the culture media were replaced with Dulbecco's modified Eagle's medium, without phenol/F-12 containing $0.02 \%$ MTT (Sigma-Aldrich). After incubation for $4 \mathrm{~h}$, the medium was replaced with $200 \mu$ of dimethyl sulfoxide per well. The absorbance was measured at a wavelength of $570 \mathrm{~nm}$ in a 96-well format plate reader (DTX880 Multimode Detector; Beckman Coulter, Brea, CA, USA) .

Wound-healing assay. The migration of native and siAMPD3transfected SCC-4 and SCC-25 cells was analyzed using a woundhealing assay. Prior to the wound-healing assay, cells were optimized to ensure a homogeneous and viable cell monolayer. Cells $\left(2 \times 10^{5}\right)$ cells were seeded in 6 -well plates 1 day before the assay, and when cell confluence reached approximately $90 \%$, a sterile, plastic 200- $\mu$ l-micropipette tip was used to artificially created a homogeneous wound on the monolayer. After creating the wound, cells were washed with phosphate-buffered saline to remove debris. Cells that had migrated into the wounded area after 4,8 , and $12 \mathrm{~h}$ were photographed at $40 \times$ magnification, and ImageJ version 1.410 (National Institutes of Health, Bethesda, MD, USA) was used to determine the migration area.

Transwell assay. A 24-well Transwell chamber (Corning Inc., Corning, NY, USA) with $8.0 \mu \mathrm{m}$ pore polycarbonate membrane filter covered by a gelatin package was used to measure invasion by SCC4 and SCC- 25 cells. The bottom membranes $(8-\mu \mathrm{m}$ aperture) of the 
A

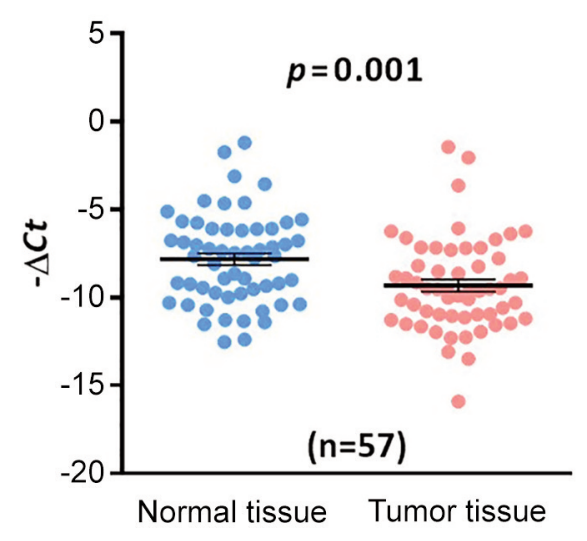

B

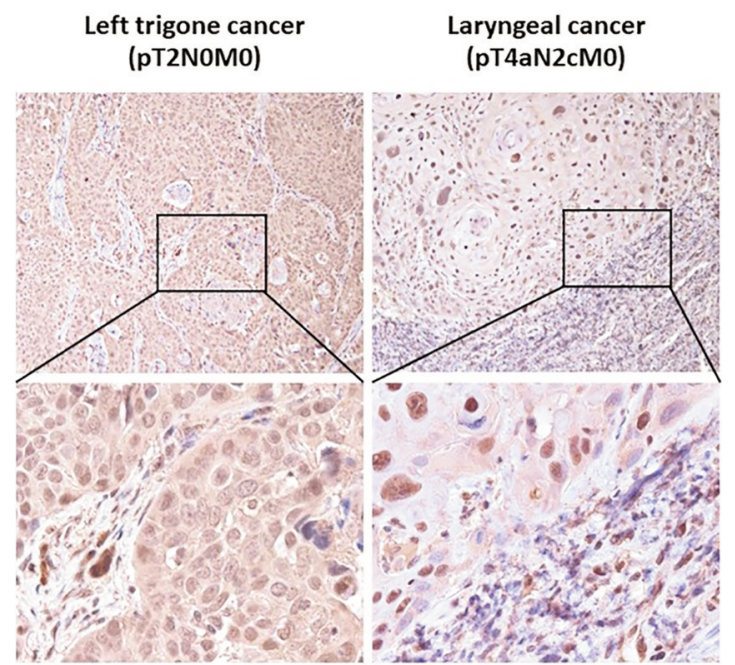

Figure 1. Expression of adenosine monophosphate deaminase 3 (AMPD3) in paired tumorous and non-tumorous tissues from patients with head and neck squamous cell carcinoma (HNSCC). A: Expression of AMPD3 was down-regulated in the tumorous tissues from 57 patients with HNSCC $(p=0.001)$ as evaluated by paired $t$-test using values of $-\triangle C t[-(C t$ of AMPD3 - Ct of $\beta$-actin gene $)]$ with four replicates of four independent experiments. Higher $-\Delta C t$ values represent higher expression levels, and vice versa. B: Representative images of immunohistochemical staining of AMPD3 in HNSCC, showing high and low expression of AMPD3 in tumorous tissues which was consistent with the results of gene expression of AMPD3. Original magnifications, main image: $\times 100$; inset: $\times 400$.

Transwell chambers were coated with Matrigel (Sigma-Aldrich) and the lower chamber was filled with $600 \mu \mathrm{l}$ of Dulbecco's modified Eagle's medium containing $10 \%$ fetal bovine serum. In the upper chamber, $5 \times 10^{5}$ cells (in $200 \mu \mathrm{l}$ ) were inoculated. The wells were removed after a 24 -h (for SCC-4 cells) or 48-h (for SCC-25) incubation at $37^{\circ} \mathrm{C}$ with $5 \% \mathrm{CO}_{2}$, and then fixed (methanol:glacial acetic acid, 3:1), stained with $0.1 \%$ crystal violet, and finally mounted. The cells which had invaded were determined by counting stained cells in five randomly selected fields using ImageJ free software, version 1.410 (National Institutes of Health).

Statistical analysis. We used SPSS version 15.0 software (SPSS, Chicago, IL, USA) and Graph Pad Prism 7.04 (GraphPad, San Diego, CA, USA) for all the statistical analyses. Student's $t$-test was used to detect differences between two groups. Overall survival was measured from study entry to death, regardless of cause. Log-rank test was used to compare Kaplan-Meier survival curves. For statistical analysis of the expression of AMPD3 of qRT-PCR, the values of $\Delta \mathrm{C} t$ were used. For MTT, wound-healing and Transwell migration assays, data were derived from three technical replicates, and the data are expressed as a mean \pm standard deviation. All tests were two-sided, and $p$-values less than 0.05 were considered statistically significant.

\section{Results}

Characteristics of patients. Patients' clinical and pathological characteristics, including gender, age, TNM and clinical staging, tumor size and survival are listed in Table I. The analyses of T-stage revealed T1 or T2 in 27 (47.4\%) patients, and T3 or T4 in $30(52.6 \%)$ patients. Further analyses of stage showed 17 (29.8\%) patients had stage I or II disease, and $40(70.2 \%)$ patients had stage 3 or 4 . All patients had M0 stage.

Analysis of expression of AMPD3 in HNSCC by qRT-PCR. To explore whether the expression of $A M P D 3$ was altered in HNSCC, we used qRT-PCR to analyze the expression of AMPD3 in cancerous and noncancerous tissues obtained from 57 patients with HNSCC. Our results demonstrated that the expression level of AMPD3 was significantly downregulated in cancerous compared with noncancerous tissues $(p=0.001)$ (Figure 1A). We also performed IHC to validate that the protein expression of AMPD3 was compatible with the gene expression level detected by qRT-PCR (Figure 1B).

Disease severity and expression of AMPD3 in HNSCC. To investigate if expression of AMPD3 was correlated with disease severity, we categorized our patients into early- and advanced-stage groups (by T staging and clinical staging) and tumor size to survey their correlation with expression of $A M P D 3$. We found the expression of $A M P D 3$ was significantly down-regulated in tumor relative to normal tissue in advanced $\mathrm{T}$ stages $(\mathrm{T} 3+\mathrm{T} 4)(p<0.001)$ but not in early stages $(\mathrm{T} 1+\mathrm{T} 2)$ (Figure 2A). Similarly, The expression of AMPD3 was also significantly lower in more advanced clinical stages (stage $3+$ stage 4) $(p<0.001)$ (Figure 2B) and in tumors larger than 3 $\mathrm{cm}(p=0.011)$ (Figure 2C). We divided these patients into high and low AMPD3 expression groups based on the cut-off value from a receiver operating characteristic curve and analyzed their correlation with survival. 

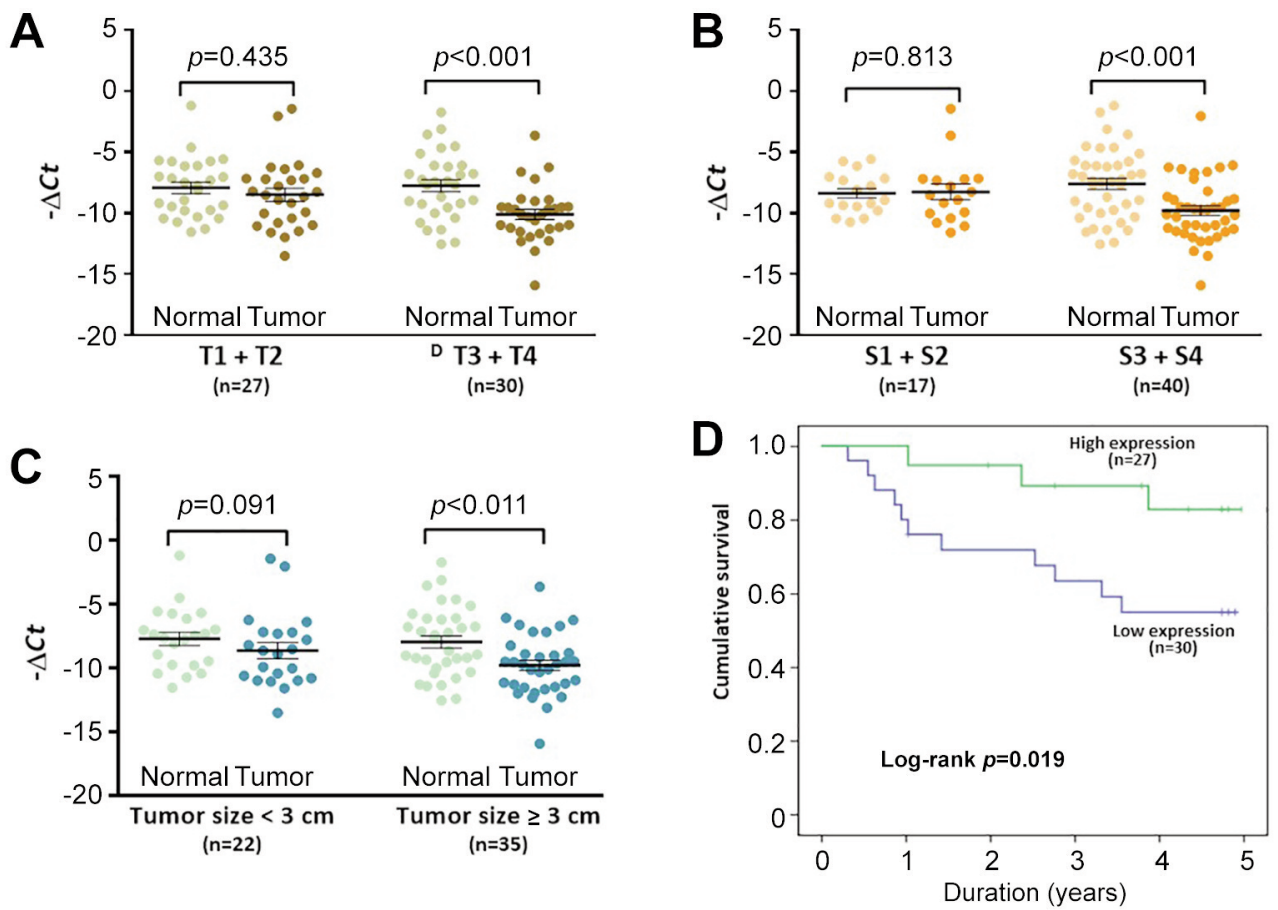

Figure 2. Down-regulation of adenosine monophosphate deaminase 3 (AMPD3) was correlated with more advanced T-stage ( $p<0.001)(A)$, more advanced clinical stage $(S)(p<0.001)(B)$ and larger tumor size $(p=0.011)(C)$ as evaluated by Mann-Whitney test using values of $-\Delta C t[-(C t$ of AMPD3 - Ct of $\beta$-actin)]. Higher- $\triangle C t$ values represent higher expression, and vice versa. D: Patients with head and neck squamous cell carcinoma with high AMPD3 expression exhibited better survival than those with low expression.
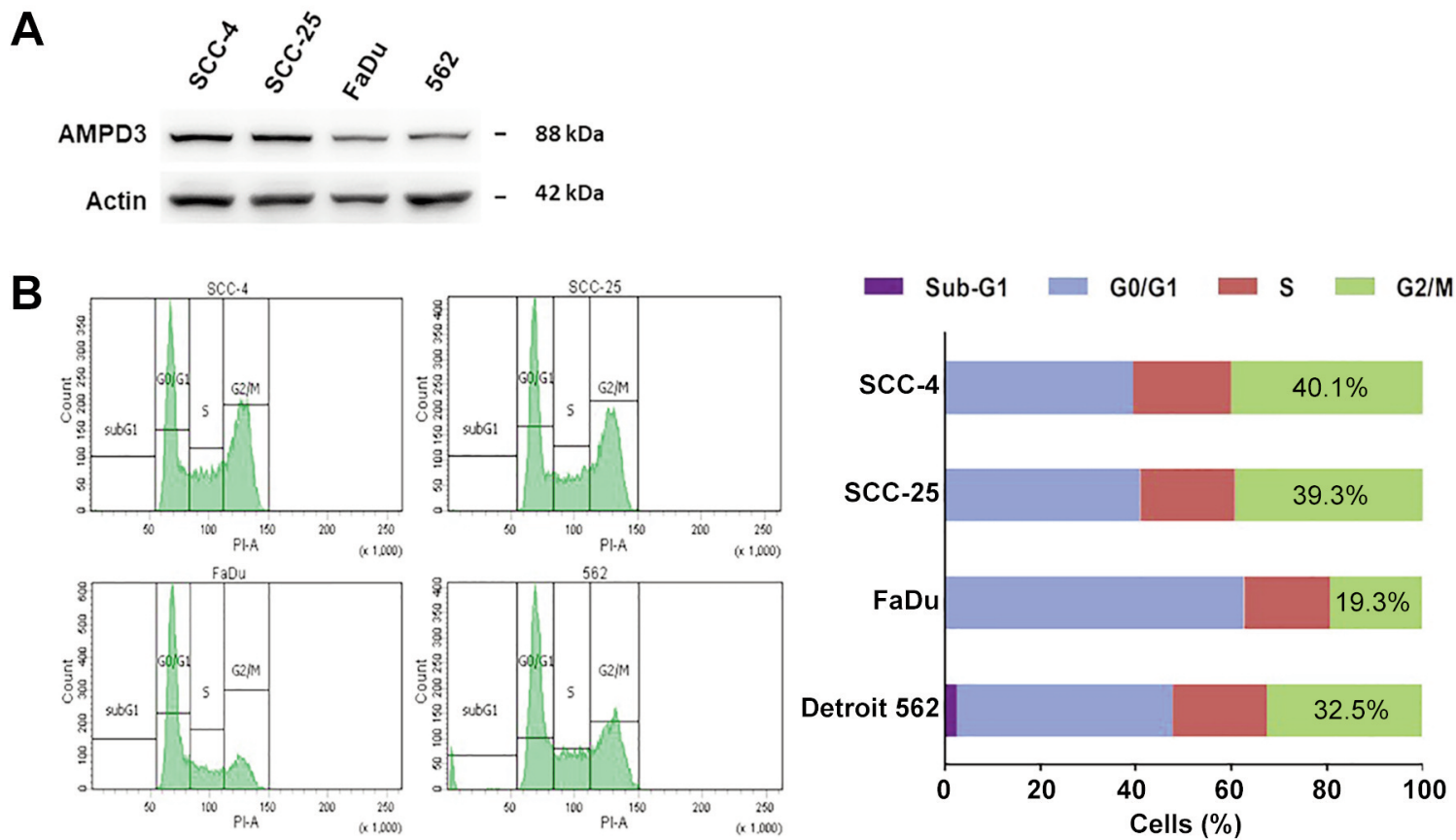

Figure 3. Adenosine monophosphate deaminase 3 (AMPD3) may enhance cell-cycle arrest. A: The expression of AMPD3 was higher in SCC-4 and SCC-25 than in in Fadu and Detroit 562 cells as detected by western blot. B: Cells with high AMPD3 expression (SCC-4 and SCC-25) exhibited a markedly increased proportion of cells in the $G_{2} / M$ phase at $24 \mathrm{~h}$ compared with cells with lower AMPD3 expression (Fadu and Detroit 562) as determined by flow cytometric cell-cycle analysis. 
As shown in the Kaplan-Meier plot (Figure 2D), the 5-year survival rate for the high AMPD3 expression group $(\mathrm{n}=27)$ was higher than that for the low-expression group $(n=30)$ ( $82 \%$ vs. $58 \%, p=0.019$ ).

Correlations between AMPD3 expression and cancer characteristics in patients with HNSCC. As the 5-year survival rate was significantly different between groups with high and low $A M P D 3$ expression, we further analyzed the correlations of expression by the clinical characteristics of these two groups (Table II). Our results showed that AMPD3 down-regulation was significantly correlated with more advanced clinical stage, tumor size and stage, as well as poorer survival (Table II).

HNSCC cell lines with high AMPD3 expression showed cellcycle arrest in $G_{2} / M$ phase. To understand whether AMPD3 affects the cell cycle, we utilized four HNSCC cell lines and determined their expression of AMPD3 then investigated their cell-cycle status. As determined by western blotting, AMPD3 was expressed in all four cell lines but was higher in SCC-4 and SCC-25 than in Fadu and Detroit 562 cells (Figure 3A). Flow cytometric cell-cycle analysis showed cell lines with high expression of AMPD3 (SCC-4 and SCC-25) had markedly high percentages of cells in the $\mathrm{G}_{2} / \mathrm{M}$ phase $(40.1 \%$ and $39.3 \%)$ (Figure 3B). In contrast, cells with low expression of AMPD3 (Fadu and Detroit 562) had fewer cells in the $\mathrm{G}_{2} / \mathrm{M}$ phase $(19.3 \%$ and $32.5 \%$ ) (Figure $3 \mathrm{~B}$ ). These results suggest that AMPD3 may have a cytostatic effect by promoting $\mathrm{G}_{2} / \mathrm{M}$ phase accumulation and inhibiting cell-cycle progression.

Antiproliferative effect of AMPD3. To elucidate the effects of $A M P D 3$ on cell proliferation, we transiently knockeddown the expression of AMPD3 in SCC-4 and SCC-25 cells (Figure 4) and performed MTT assays to determine the cell growth. Evaluation up to $48 \mathrm{~h}$ after knockdown showed the proliferation of SCC-4 was not significantly affected by $A M P D 3$ silencing (Figure 4C). In contrast, at $24 \mathrm{~h}$ after $A M P D 3$ knockdown the cell growth was markedly increased in SCC-25 cells $(p<0.001)$ (Figure 4D). These results suggest that $A M P D 3$ may have antiproliferative potential.

Down-regulation of AMPD3 did not enhance the migration and invasion of SCC-4 and SCC-25 cells. We performed wound-healing and Transwell assays to assess the effect of AMPD3 on the migratory and invasive abilities of SCC-4 and SCC-25 cells. We found in both SCC-4 and SCC-25 cells that migration was significantly lower at 8 to $12 \mathrm{~h}$ in cells after AMPD3 knockdown than that in cells treated with control siRNA (Figure 5A). After incubating for $24 \mathrm{~h}$ (SCC4) and $48 \mathrm{~h}$ (SCC-25) in Transwell chambers, the number of invaded cells was markedly reduced in both SCC-4 and
A

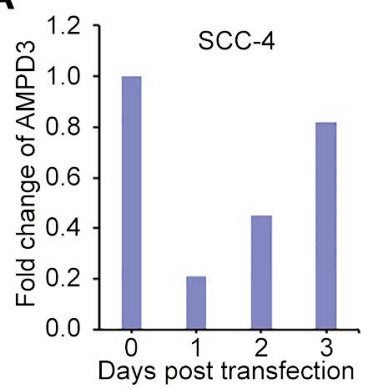

B
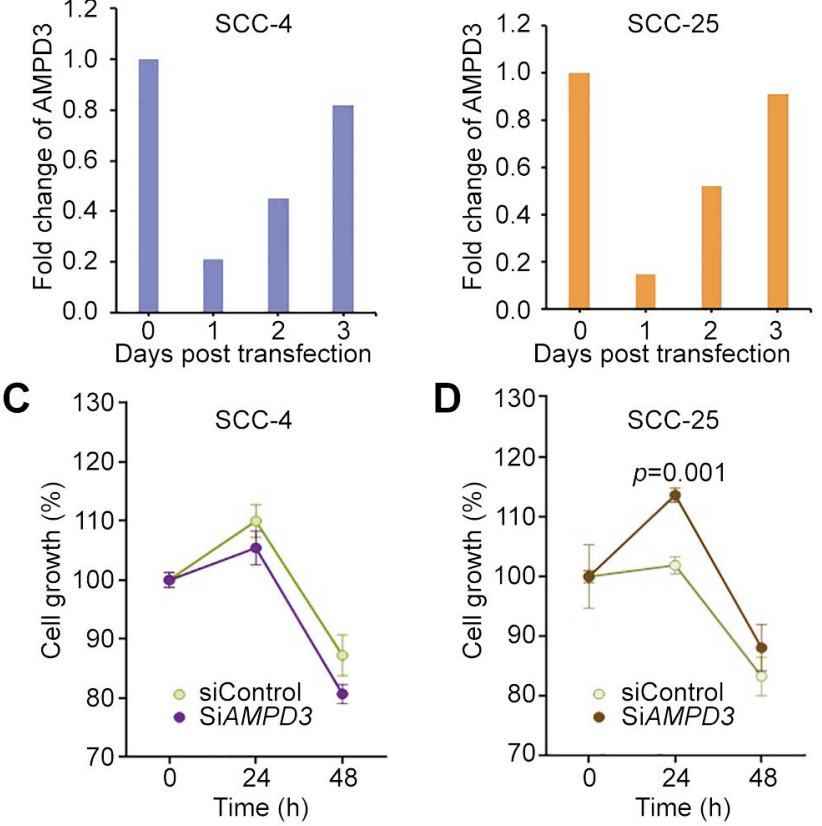

Figure 4. Adenosine monophosphate deaminase 3 (AMPD3) may possess antiproliferative potential. A: AMPD3 expression in SCC-4 cells after transfection with AMPD3 siRNA. B: AMPD3 expression in SCC25 cells after transfection with AMPD3 siRNA. C: The proliferation of SCC-4 cells over 2 days was not significantly affected by AMPD3 knockdown. D: In SCC-25 cells, after AMPD3 knockdown the growth at $24 h$ was markedly increased $(p<0.001)$. $-\Delta C t$ values $[-(C t$ of AMPD3 - Ct of $\beta$-actin gene)] from four replicates of four independent experiments are shown. Higher $-\Delta C t$ values represent higher expression levels, and vice versa.

SCC-25 cells with AMPD3 knockdown compared with cells treated with control siRNA (Figure 5B). These results suggest that $A M P D 3$ down-regulation did not enhance but in fact weakened the migratory and invasive abilities of SCC4 and SCC-25 cells.

\section{Discussion}

The present study demonstrated that AMPD3 was significantly down-regulated in HNSCC tissue and was correlated with disease severity. Patients with low expression of AMPD3 had a worse survival than those with high expression. In vitro studies demonstrated cells with high expression of AMPD3 (SCC-4 and SCC-25) exhibited more cell-cycle arrest in $\mathrm{G}_{2} / \mathrm{M}$ phase than those with lower expression of AMPD3 (Fadu and Detroit562). However, $A M P D 3$ knockdown did not enhance the migration and invasion of SCC-4 and SCC-25 cells. AMPD3 knockdown reduced proliferation of SCC-4 cells mildly but increased proliferation of SCC-25 cells significantly. 
A
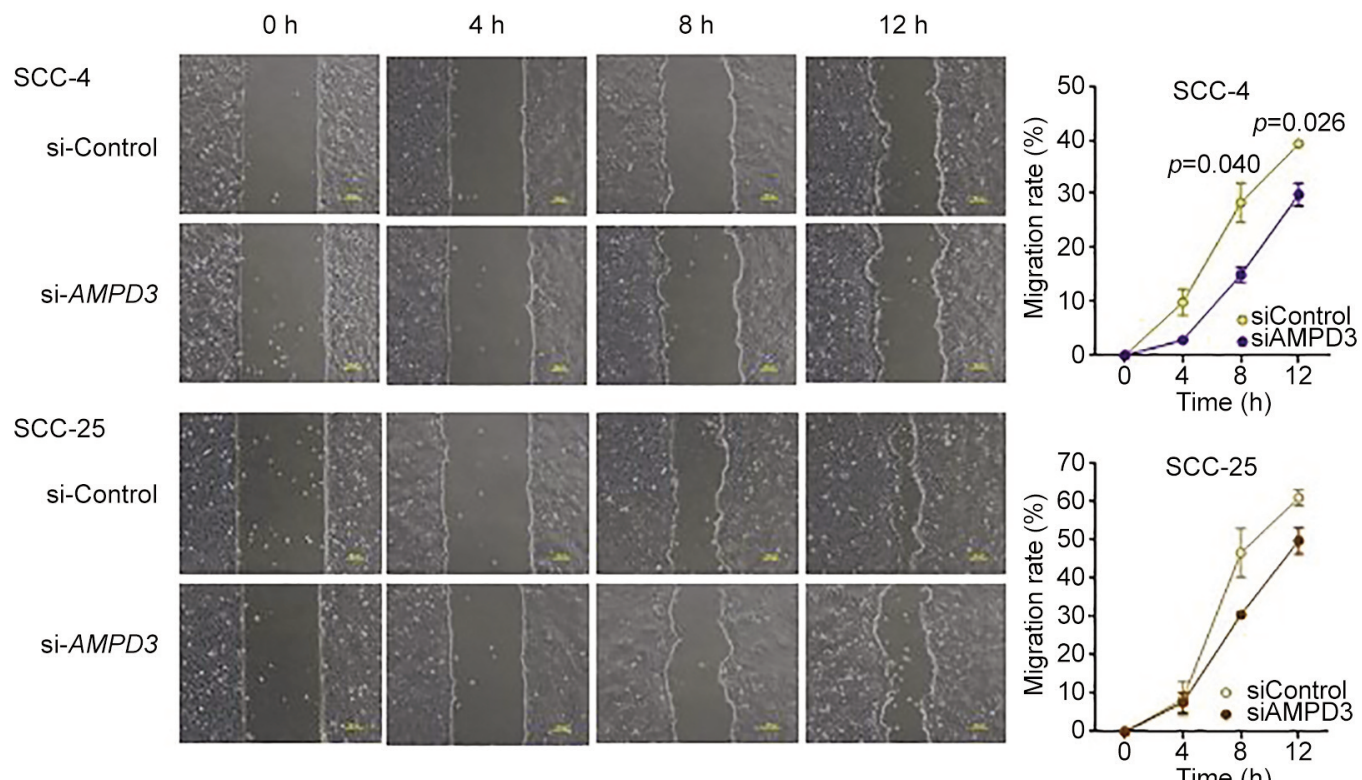

B

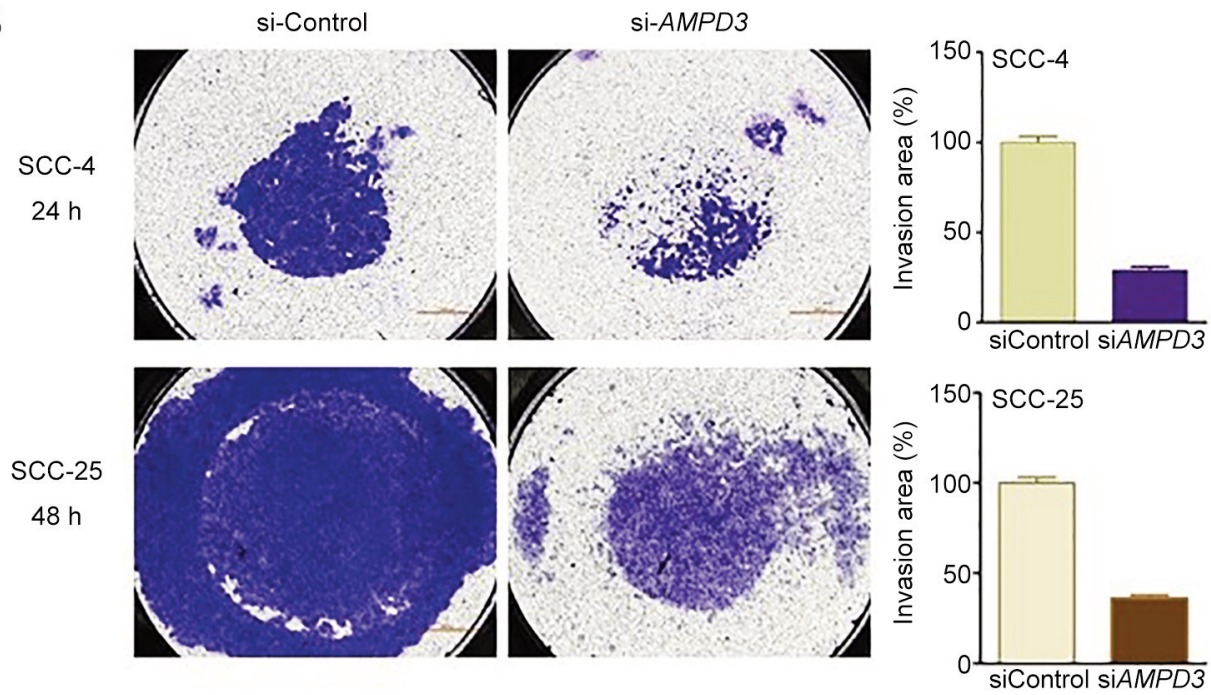

Figure 5. Adenosine monophosphate deaminase 3 (AMPD3) down-regulation weakened the migratory and invasive abilities of SCC-4 and SCC-25 cells. AMPD3 expression was effectively down-regulated in SCC-4 cells (A) and SCC-25 (B) transfected with AMPD3 siRNA, as determined by real-time quantitative reverse transcriptase-polymerase chain reaction. C: In both SCC-4 and SCC-25 cells, migration for 8 to $12 \mathrm{~h}$ was significantly lower in cells after AMPD3 was knocked down than that in cells treated with control siRNA. D: After incubating for $24 \mathrm{~h}$ (SCC-4) and $48 \mathrm{~h}$ (SCC$25)$ in Transwell chambers, the number of invaded cells was markedly reduced in both lines with AMPD3 knockdown compared with cells treated with control SiRNA.

To our best knowledge, the roles of $A M P D 3$ gene in HNSCC are still uncertain. AMPD3 gene encodes a highly regulated enzyme that plays an important role in energy charge stabilization and nucleotide metabolism (10). AMPDs also play an important role in purine and urate metabolism (15). AMPD deficiency may change the level of adenosine, an important bioactive molecule. AMP-activated protein kinase (AMPK), controlled by intracellular AMP, has an important role as an energy sensor. Therefore, AMPD may control the systemic metabolic status by changing AMPK activity through the level of AMP.

Our results showed that expression of AMPD3 was reduced in tumorous tissues of HNSCC and was related to T-stage and clinical stage. We propose a possible explanation 
for these observations. AMPD3 is ubiquitously expressed, and mice with AMPD3 deficiency showed increased levels of ATP in their cells (16). During periods of energy imbalance, AMP in the adenylate pool is removed by activated AMPD (16). A rise in AMP levels, resulting in the activation of AMPK, induces cellular stress and leads to cellcycle arrest (17). The suppression of tumor progression by AMPK has been reported (18-20). Therefore, increasing the level of AMP as a result of AMPD3 knockdown may promote the activation of AMPK, which can subsequently inhibit anabolic pathways that are important to cancer proliferation and cell survival (21-23). In our study, high $A M P D 3$ expression was associated with a greater proportion of cells arrested in the $\mathrm{G}_{2} / \mathrm{M}$ phase and with reduced cell growth, which implies that AMPD3 may have an antiproliferative potential. We also observed that the survival of patients with high expression of AMPD3 was better than that of those with low AMPD3 expression. However, downregulation of $A M P D 3$ did not enhance the migration and invasion abilities of cancer cell. It is possible that the role of $A M P D 3$ in cancer is mainly in the control of cell proliferation and is independent of cell migration and invasion.

In conclusion, to our knowledge, this is the first study that illustrated the role of $A M P D 3$ gene in HNSCC. We found a high expression of $A M P D 3$ may represent a good prognostic biomarker in HNSCC: Patients with low expression of $A M P D 3$ had poor survival. $\mathrm{G}_{2} / \mathrm{M}$ cell-cycle arrest and energy imbalance by up-regulation of $A M P D 3$ may influence patients' survival due to its effects on the ability of proliferation.

\section{Conflicts of Interest}

The Authors declare no conflicts of interest.

\section{Authors' Contributions}

CM Hsu: Conceptualization, funding acquisition, supervision, writing - original draft, writing - review and editing. SF Chang: Investigation and methodology. YT Tsai: Investigation, project administration. MS Tsai: Data curation, formal analysis, software and writing - original draft. GH Chang: Investigation, methodology and formal analysis. HC Chen: Data curation, software and validation. PC Huang: Conceptualization. Ko CA: Investigation and data curation. $\mathrm{CY} \mathrm{Wu}$ : Resources and software. SF Lin: Conceptualization and writing - review and editing. MY Yang: Conceptualization, and writing - original draft, review and editing.

\section{Acknowledgements}

This work was supported in part by grants from Chang Gung Memorial Hospital (grant numbers $\mathrm{CMRPG}_{6} \mathrm{G}_{0} 421, \mathrm{CMRPG}_{6} \mathrm{G}_{0} 422$, $\mathrm{CMRPG}_{6} \mathrm{G}_{0} 423, \mathrm{CMRPG}_{6} \mathrm{~J}_{0} 251$, and $\mathrm{CMRPG}_{6} \mathrm{~K}_{0} 391$ ).

\section{References}

1 Mehanna H, Paleri V, West CM and Nutting C: Head and neck cancer-Part 1: Epidemiology, presentation, and prevention. BMJ 341: c4684, 2010. PMID: 20855405. DOI: 10.1136/ bmj.c4684

2 Mehanna H, Paleri V, West CM and Nutting C: Head and neck cancer-part 1: epidemiology, presentation, and preservation. Clin Otolaryngol 36(1): 65-68, 2011. PMID: 21414154. DOI: 10.1111/j.1749-4486.2010.02231.x

3 Jou A and Hess J: Epidemiology and molecular biology of head and neck cancer. Oncol Res Treat 40(6): 328-332, 2017. PMID: 28531899. DOI: $10.1159 / 000477127$

4 Health Promotion Administration Ministry of Health and Welfare, Taiwan. Cancer Registry Annual Report. Available at: https://www.hpa.gov.tw/Pages/ashx/File.ashx?FilePath= /File/At tach/6069/File_5962.pdf [Last accessed on December 10th, 2021]

5 Boscolo-Rizzo P, Zorzi M, Del Mistro A, Da Mosto MC, Tirelli G, Buzzoni C, Rugge M, Polesel J, Guzzinati S and AIRTUM Working Group: The evolution of the epidemiological landscape of head and neck cancer in Italy: Is there evidence for an increase in the incidence of potentially HPV-related carcinomas? PLoS One 13(2): e0192621, 2018. PMID: 29415020. DOI: 10.1371/journal.pone.0192621

6 Mourad M, Jetmore T, Jategaonkar AA, Moubayed S, Moshier E and Urken ML: Epidemiological trends of head and neck cancer in the United States: a SEER population study. J Oral Maxillofac Surg 75(12): 2562-2572, 2017. PMID: 28618252. DOI: $10.1016 /$ j.joms.2017.05.008

7 Iocca O, Farcomeni A, Di Rocco A, Di Maio P, Golusinski P, Pardiñas López S, Savo A, Pellini R and Spriano G: Locally advanced squamous cell carcinoma of the head and neck: A systematic review and Bayesian network meta-analysis of the currently available treatment options. Oral Oncol 80: 40-51, 2018. PMID: 29706187. DOI: 10.1016/j.oraloncology.2018. 03.001

8 Mahnke DK and Sabina RL: Calcium activates erythrocyte AMP deaminase [isoform E (AMPD3)] through a protein-protein interaction between calmodulin and the $\mathrm{N}$-terminal domain of the AMPD3 polypeptide. Biochemistry 44(14): 5551-5559, 2005. PMID: 15807549. DOI: 10.1021/bi048121p

9 Morisaki T, Sermsuvitayawong K, Wang X, Nagabukuro A, Matsuda Y, Ogasawara N, Mineo I, Morisaki H and Mukai T: Molecular analysis of mouse Ampd3 gene encoding heart-type isoform of AMP deaminase. Adv Exp Med Biol 431: 337-340, 1998. PMID: 9598087. DOI: 10.1007/978-1-4615-5381-6_67

10 Yamada Y, Goto H, Wakamatsu N and Ogasawara N: A rare case of complete human erythrocyte AMP deaminase deficiency due to two novel missense mutations in AMPD3. Hum Mutat 17(1): 78, 2001. PMID: 11139257. DOI: 10.1002/10981004(2001)17:1<78::AID-HUMU21>3.0.CO;2-B

11 Fishbein WN, Sabina RL, Ogasawara N and Holmes EW: Immunologic evidence for three isoforms of AMP deaminase (AMPD) in mature skeletal muscle. Biochim Biophys Acta 1163(1): 97-104, 1993. PMID: 8476935. DOI: 10.1016/01674838(93)90284-X

12 Plaideau C, Lai YC, Kviklyte S, Zanou N, Löfgren L, Andersén H, Vertommen D, Gailly P, Hue L, Bohlooly-Y M, Hallén S and Rider MH: Effects of pharmacological AMP deaminase 
inhibition and Ampd1 deletion on nucleotide levels and AMPK activation in contracting skeletal muscle. Chem Biol 21(11): 1497-1510, 2014. PMID: 25459662. DOI: 10.1016/ j.chembiol.2014.09.013

13 Wong M, Funasaka K, Obayashi T, Miyahara R, Hirooka Y, Hamaguchi M, Goto $\mathrm{H}$ and Senga T: AMPD3 is associated with the malignant characteristics of gastrointestinal stromal tumors. Oncol Lett 13(3): 1281-1287, 2017. PMID: 28454247. DOI: 10.3892/ol.2016.5532

14 Amin MB, Edge SB, Greene FL, Byrd DR, Brookland RK, Washington MK, Gershenwald JE, Compton CC, Hess KR, Sullivan DC, Jessup JM, Brierley JD, Gaspar LE, Schilsky RL, Balch CM, Winchester DP, Asare EA, Martin Madera, Gress DM and Meyer LR (eds.): AJCC Cancer Staging Manual, Eighth Edition. Cham, Switzerland, Springer International Publishing, 2017.

15 Morisaki $H$ and Morisaki T: [AMPD genes and urate metabolism]. Nihon Rinsho 66(4): 771-777, 2008. PMID: 18409530 .

16 Cheng J, Morisaki H, Toyama K, Ikawa M, Okabe M and Morisaki T: AMPD3-deficient mice exhibit increased erythrocyte ATP levels but anemia not improved due to PK deficiency. Genes Cells 17(11): 913-922, 2012. PMID: 23078545. DOI: 10.1111/gtc. 12006

17 Hardie DG: New roles for the LKB1->AMPK pathway. Curr Opin Cell Biol 17(2): 167-173, 2005. PMID: 15780593. DOI: 10.1016/j.ceb.2005.01.006

18 Nguyen TMD, Klett D, Filliatreau L and Combarnous Y: Inhibition by fluoxetine of LH-stimulated cyclic AMP synthesis in tumor Leydig cells partly involves AMPK activation. PLoS One 14(6): e0217519, 2019. PMID: 31163038. DOI: 10.1371/ journal.pone.0217519
19 Wang J, Liu Z, Feng X, Gao S, Xu S and Liu P: Tumor suppressor gene ING3 induces cardiomyocyte hypertrophy via inhibition of AMPK and activation of p38 MAPK signaling. Arch Biochem Biophys 562: 22-30, 2014. PMID: 25151306. DOI: $10.1016 /$ j.abb.2014.08.007

20 Motoshima H, Goldstein BJ, Igata M and Araki E: AMPK and cell proliferation-AMPK as a therapeutic target for atherosclerosis and cancer. J Physiol 574(Pt 1): 63-71, 2006. PMID: 16613876. DOI: 10.1113/jphysiol.2006.108324

21 Ríos M, Foretz M, Viollet B, Prieto A, Fraga M, Costoya JA and Señarís R: AMPK activation by oncogenesis is required to maintain cancer cell proliferation in astrocytic tumors. Cancer Res 73(8): 2628-2638, 2013. PMID: 23370326. DOI: 10.1158/ 0008-5472.CAN-12-0861

22 Liu M, Zhang Z, Wang H, Chen X and Jin C: Activation of AMPK by metformin promotes renal cancer cell proliferation under glucose deprivation through its interaction with PKM2. Int J Biol Sci 15(3): 617-627, 2019. PMID: 30745848. DOI: 10.7150/ijbs.29689

23 Zhang P, Lai ZL, Chen HF, Zhang M, Wang A, Jia T, Sun WQ, Zhu XM, Chen XF, Zhao Z and Zhang J: Curcumin synergizes with 5-fluorouracil by impairing AMPK/ULK1-dependent autophagy, AKT activity and enhancing apoptosis in colon cancer cells with tumor growth inhibition in xenograft mice. J Exp Clin Cancer Res 36(1): 190, 2017. PMID: 29273065. DOI: 10.1186/s13046-017-0661-7
Received July 21, 2021

Revised December 4, 2021

Accepted December 10, 2021 